\title{
Pendampingan Pengolahan Limbah Serabut Kelapa menjadi Cocofiber dan Cocopeat di Desa Manggar Raya
}

\author{
Saleh Hidayat ${ }^{1}$, Meli Astriani ${ }^{1 *}$, Wulandari Saputri ${ }^{1}$, Nita Nuraini ${ }^{1}$
}

1Universitas Muhammadiyah Palembang, Jl. Jenderal Ahmad Yani 13 Ulu Seberang Ulu II, Palembang, Indonesia, 30263

*Email koresponden: meliastriani.g201@gmail.com

\section{ARTICLE INFO \\ Article history \\ Received: 06 Agt 2021 \\ Accepted: 22 Nov 2021 \\ Published: 31 Des 2021}

\section{Kata kunci:}

Cocofiber;

Cocopeat;

Kelapa.

Kuliah Kerja Nyata

Mandiri;

\begin{abstract}
A B S T R A K
Background: Desa Manggar Raya merupakan salah satu desa yang terletak di Kecamatan Tanjung Lago, Kabupaten Banyuasin, Provinsi Sumatera Selatan. Desa Manggar Raya merupakan salah satu penghasil kelapa terbesar, namun masyarakat hanya menggunakan daging buah dan air kelapa untuk dijual, sedangkan serabut kelapa dibiarkan menjadi limbah oleh masyarakat desa. Kegiatan Pengabdian Kolaboratif dengan mahasiswa kuliah kerja nyata mandiri bertujuan untuk membantu dalam pengolahan limbah sabut kelapa secara manual menjadi cocofiber dan cocopeat. Metode: Peserta dalam kegiatan terdiri atas 21 warga Desa Manggar Raya. Metode partisipatif yang digunakan dalam pendampingan pengabdian masyarakat yang mencakup pemberian materi, praktik, diskusi dan evaluasi. Hasil: Respon yang positif dari peserta kegiatan. Peserta merasa puas dengan kegiatan dan memperoleh pengetahuan tentang pengolahan limbah yang diberikan. Kesimpulan: Pendampingan pengolahan serabut kelapa kepada masyarakat mampu meningkatkan pengetahuan sebesar $85 \%$ tentang cara mengolah serabut kelapa menjadi cocofiber dan cocopeat. Selain itu peserta memperoleh keterampilan membuat pot hias dari serabut kelapa untuk meningkatkan nilai jual cocofiber. Prospek bisnis kedepannya diharapkan masyarakat desa Manggar Raya dapat menjadi sentra industri pengolahan serabut kelapa di Sumatera Selatan.
\end{abstract}

\section{A B S T R A C T}

Background: Manggar Raya Village is one of the villages located in Tanjung Lago District, Banyuasin Regency, South Sumatra Province. Manggar Raya village is one of the largest coconut producers. Still, the community only uses fruit flesh and coconut water to sell, while the coconut fiber is left as waste by the village community. Collaborative Service Activities with independent real-life college students aim to assist in the manual processing of coconut coir waste into cocofiber and cocopeat. Methods: Participants in the activity consisted of 21 residents of Manggar Raya Village. The participatory method used in community service assistance which includes the provision of material, practice, discussion and evaluation. Result: Positive response from activity participants. Participants were satisfied with the activities and learned about the waste management provided. Conclusion: Assistance in processing coconut fiber to the community can increase knowledge by $85 \%$ about how to process coconut fiber into cocofiber and cocopeat. In addition, participants gained the skills to make decorative pots from coconut fibers to increase the selling value of cocofiber. In the future, it is hoped that the people of Manggar Raya village can become the center of the coconut fiber processing industry in South Sumatra.

2021 by authors. Lisensi Jurnal Solma, UHAMKA, Jakarta. Artikel ini bersifat open access yang didistribusikan di bawah syarat dan ketentuan Creative Commons Attribution (CC-BY) license.

\section{PENDAHULUAN}

Desa Manggar Raya, yang terletak di Kecamatan Tanjung Lago, Kabupaten Banyuasin, Provinsi Sumatera Selatan, dengan letak geografis berada antara $2^{\circ} 39^{\prime} 12.5^{\prime \prime} S 104^{\circ} 28^{\prime} 57.0^{\prime \prime}$ E. Potensi yang ada di Desa Manggar Raya seperti sumber daya alam perkebunan dan hasil pertanian. Desa 
Manggar Raya juga disebut sebagai penghasil kelapa terbesar untuk memenuhi penjualan pangsa ekspor. Mayoritas penduduknya bermata pencarian sebagai petani. Sebagian besar ekonomi penduduk didukung sektor usaha perkebunan kelapa sawit dan kelapa. Aksesibilitas lokasi desa sangat sulit dijangkau karena dikelilingi oleh sungai, sedangkan transportasi menuju tempat ini hanya menggunakan perahu melalui jalur perairan. Hasil perkebunan yang dijual adalah bagian daging kelapa, untuk bagian luar atau serabut kelapa tidak dimanfaatkan. Sepanjang perjalanan menuju desa Manggar Raya banyak ditemukan limbah serabut kelapa yang sangat melimpah. Hanum, (2015); Dalimunthe et al., (2019) menyebutkan bahwa serabut kelapa dan tempurung masih banyak dibiarkan saja menjadi limbah. Banyak masyarakat yang tidak mengetahui pengolahan limbah serabut kelapa. Sebagian dari masyarakat menghilangkan limbah serabut kelapa dengan cara dibakar. Cara ini sangat tidak ramah lingkungan dan berdampak pada peningkatan emisi gas CO2 di bumi (Sulistyono, 2012). Pengetahuan dan keterampilan masyarakat untuk mengolah serabut kelapa menjadi barang yang bernilai jual masih sangat rendah (Novianti \& Pertiwi, 2018).

Sabut kelapa merupakan salah satu penyusun kelapa bagian terluar yang dapat diolah kembali menjadi produk bernilai bagi pasar domestik. Indahyani, (2011) menyebutkan bahwa komponen dari sabut kelapa bersifat ramah lingkungan dan menjadi bagian dari program terkait pengembangan social entrepreneurship, sustainable design, green design. Dengan demikian, pemanfaatan limbah sabut kelapa menjadi dapat menjadi lebih bernilai ekonomis dan tentunya sangat berdampak positif pada masyarakat (Trianto, M., Marisa, F., 2020).

Bersamaan dengan upaya untuk mengurangi limbah, serabut kelapa dapat dijadikan media tanaman hias yang berupa coco fiber dan coco peat (Allwar et al., 2018). Hal ini sejalan dengan Indahyani, (2011); Efrita et al., (2020) mengemukakan sabut kelapa ini dapat dikembangkan menjadi beragam produk, antara lain coco peat, cocofibre, dan cocofiber. Produk cocofiber dan coco peat merupakan dua produk turunan dari sabut kelapa yang melalui beberapa penelitian dapat diolah menjadi barang yang bernilai jual (Haryanto \& Prasetyo, 2019). Pengolahan sabut kelapa secara manual dapat dipraktekkan oleh masyarakat tanpa menggunakan peralatan yang mahal. Pengolahan sabut kelapa menjadi sangat penting bagi masyarakat desa manggar sebagai penghasil kelapa (Astuti, 2019). Dari beberapa penelitian menyatakan bahwa hasil terbaik pengolahan sabut kelapa yaitu melakukan perendaman 6 hari sehingga diperoleh adalah coco fiber $(16,66 \%)$ terbagi atas $13 \%$ serat sabut panjang dan serat sabut pendek sebesar $3,66 \%$. Produk coco peat yang dihasilkan mencapai $48,30 \%$. Perlakuan perendaman sabut kelapa yang semakin lama dapat menghasilkan persentase sabut yang terurai menjadi Coco fiber dan Coco peat (Sepriyanto. \& Subama, 2018).

Pengelolaan coco fiber dapat dijadikan media tanaman hias seperti kokedama yang juga menjadi sarana pengembangan kemampuan bioentrepreneurship masyarakat sehingga menjadi lebih mandiri secara ekonomi (Saputra et al., 2019). Kokedama itu sendiri merupakan teknik menanam dari jepang dengan memanfaatkan lumut sebagai media tanam, namun di Indonesia lumut digantikan oleh serabut kelapa (Trahutami \& Wiyatasari, 2019). Teknik penanaman dengan kokedama juga membuka peluang bisnis (Garneti, 2017), khususnya di masa pandemi karena meningkatkan nilai estetik dan nilai jual tanaman hias. Tanaman kokedama juga sudah menjadi salah satu ladang ekonomi bagi masyarakat dikarenakan masih banyak belum mengenal tanaman hias yang bernilai jual tinggi. Keunikan kokedama dapat menaikkan harga tanaman hias menjadi 30-40\% (Hamidah, 2015).

Coco peat merupakan butiran halus hasil olahan serabut kelapa sebagai media tanam. Butiran halus dari serabut kelapa paling banyak dan mudah ditemukan di negara-negara tropis seperti Indonesia (Widoyono, 2011). Sifat media tanam coco peat dapat menetralkan keasaman tanah dengan cara menahan kandungan air dan unsur kimia pupuk. Sifat coco peat ini memberikan 
keunggulan yang dapat digunakan sebagai media tanam yang baik untuk pertumbuhan dari beberapa tanaman hortikultura dan media untuk tanaman di rumah kaca (Sepriyanto. \& Subama, 2018).

Pengolahan coco fiber dan coco peat hingga menjadi produk yang dapat dimanfaatkan perlu menghilangkan zat tanin yang dapat menjadi senyawa perhambat dalam pertumbuhan tanaman (Supraptiningsih, L. K., Hattarina, 2018). Sukarman et al., (2012) menyatakan bahwa zat tanin merupakan senyawa yang dapat menjadi penghalang mekanis dalam penyerapan unsur hara. Oleh karena itu, perlu pengolahan serabut kelapa dengan menghilangkan zat tanin menggunakan beberapa perlakuan. Untuk itu, mahasiswa KKN sebagai bagian dari agen of change dan masyarakat setempat perlu dibekali ragam keterampilan mengelola serabut kelapa ini hingga nantinya dapat berimbas menghasilkan coco fiber dan coco peat sebagai media tanam yang bernilai ekonomi untuk pendapatan masyarakat (Allwar et al., 2018). Oleh karena itu, perlu dilakukan kegiatan "Pendampingan Pengolahan Manual Limbah Serabut Kelapa menjadi Coco fiber dan Coco peat"(Darmayanti et al., 2013).

\section{MASALAH}

Limbah serabut kelapa di daerah Tanjung Lago Kabupaten Banyuasin sangat melimpah dan tidak dimanfaatkan masyarakat sekitar. Banyak masyarakat yang tidak mengetahui pengolahan limbah serabut kelapa. Sebagian masyarakat menghilangkan limbah serabut kelapa dengan cara dibakar. Hal ini tentu menjadi permasalahan karena dapat meningkatkan emisi gas dan limbah yang semakin menumpuk. Solusi yang diberikan bagi masyarakat pesisir sungai khususnya desa Manggar Raya adalah pendampingan pengolahan limbah serabut kelapa menjadi media tanam yang bernilai jual. Serabut kelapa yang tinggi zat tannin perlu dihilangkan dengan beberapa perlakuan sehingga dapat meningkatkan penjualan produk. Melalui pendampingan kepada masyarakat ini diharapkan masyarakat dapat mengolah serabut kelapa menjadi produk coco fiber dan coco peat yang memiliki nilai jual dan ramah lingkungan.

\section{METODE PELAKSANAAN}

Kegiatan pengabdian kolaboratif dengan mahasiswa KKN di Desa Manggar Raya, Kec Tanjung Lago, Kab Banyuasin, Provinsi Sumatera Selatan dilakukan secara offline. Pendampingan kepada masyarakat ini menggunakan metode partisipatif. Alur kegiatan PKM meliputi kegiatan observasi di lapangan dalam menemukan permasalahan dan potensi daerah hingga memberikan solusi melalui kegiatan pendampingan mengolah limbah serabut kelapa menjadi produk dengan prospek yang menjanjikan bagi masyarakat desa Manggar Raya. Penjelasan alur pengabdian ini disajikan oleh Gambar_1. 


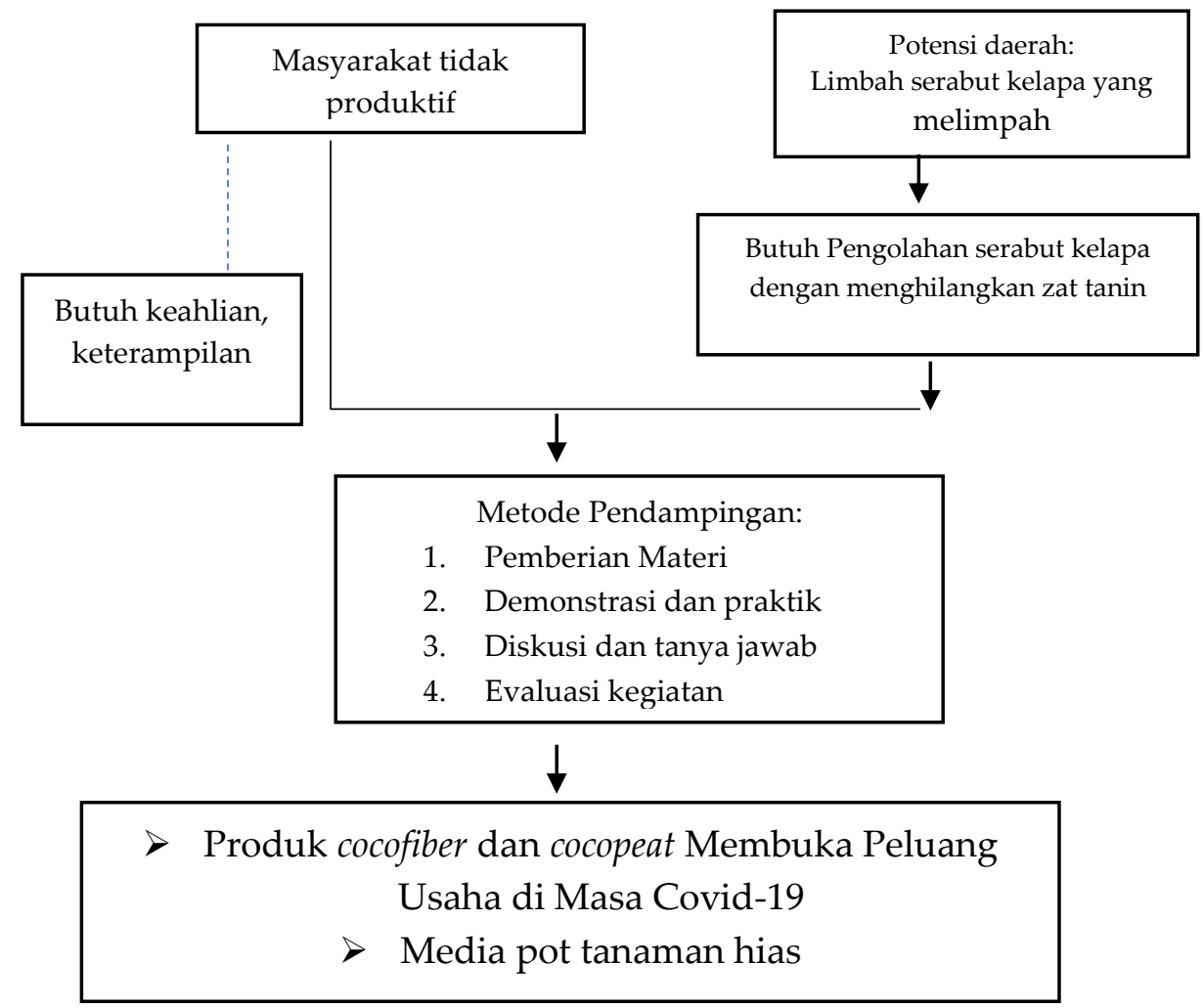

Gambar 1. Alur Kegiatan Pengabdian kepada Masyarakat Manggar Raya

Kegiatan transfer pengetahuan dilakukan melalui pendampingan dan demonstrasi pengolahan limbah sampai memanfaatkan menjadi media tanam. Pelaksanaan pengabdian kolaboratif dilakukan pada tanggal 12 Februari 2021. Adapun prosedur kegiatan pendampingan sebagai berikut.

1. Pemberian Materi

Materi pengolahan limbah serabut kelapa dijelaskan oleh ketua tim pengabdian. Materi yang dijelaskan berkaitan dengan peluang limbah serabut kelapa, dampak pengolahan sabut kelapa yang dibakar, manfaat limbah serabut kelapa untuk media tanam.

2. Demonstrasi dan praktik cara pengolahan limbah serabut kelapa menjadi coco fiber dan coco peat. Berikut prosedur pembuatan coco fiber dan coco peat:

a. Limbah Serabut kelapa yg sudah lepas dari kelapa disiapkan sebanyak 1 karung.

b. Lalu siapkan baskom/drum untuk merendam serabut kelapa, Langkah kedua ini bisa juga diganti dengan merendamkan serabut kelapa dalam karung yang diikat dan direndam dalam air mengalir (sungai).

c. Perendaman serabut kelapa dilakukan selama 6-7 hari. Jika dilakukan dalam baskom air diganti setiap hari untuk menghilangkan zat tannin.

d. Hari terakhir, serabut kelapa yg masih basah lalu dipukul secara manual dengan palu untuk memisahkan coco fiber dan coco peat.

e. Kemudian dijemur hingga kering

3. Diskusi dan tanya jawab

4. Pemberian angket merupakan bentuk evaluasi terhadap respon masyarakat setelah mengikuti kegiatan, kemudian dilakukan penggalian saran dari peserta guna perbaikan kegiatan serupa selanjutnya. 


\section{HASIL DAN PEMBAHASAN}

\section{Penjelasan Peluang Limbah Serabut Kelapa Menjadi Coco fiber dan Coco peat}

Kegiatan PKM Kolaboratif diawali dengan pembukaan dari kepala Desa Manggar Raya, Bapak Ahmad Bayu Aji. Beliau menyatakan senang sekali dengan adanya kegiatan PKM Kolaboratif dengan mahasiswa KKN. Bahkan beliau berharap akan masih banyak lagi kegiatankegiatan serupa di desanya. Kemudian, kegiatan dilanjutkan dengan penjelasan materi limbah serabut kelapa, coco fiber, dan coco peat. Para peserta sudah diberikan leafleat materi yang disampaikan. Para peserta nampak antusias mendengarkan penjelasan dari pemateri. Kegiatan juga dalam rangka menumbuhkan kemampuan bioentrepreneurship dapat menjadikan masyarakat lebih mandiri secara ekonomi (Juariyah, 2010; Persada \& Anggita Ramadhani, 2015). Kegiatan ini disajikan pada Gambar 2.

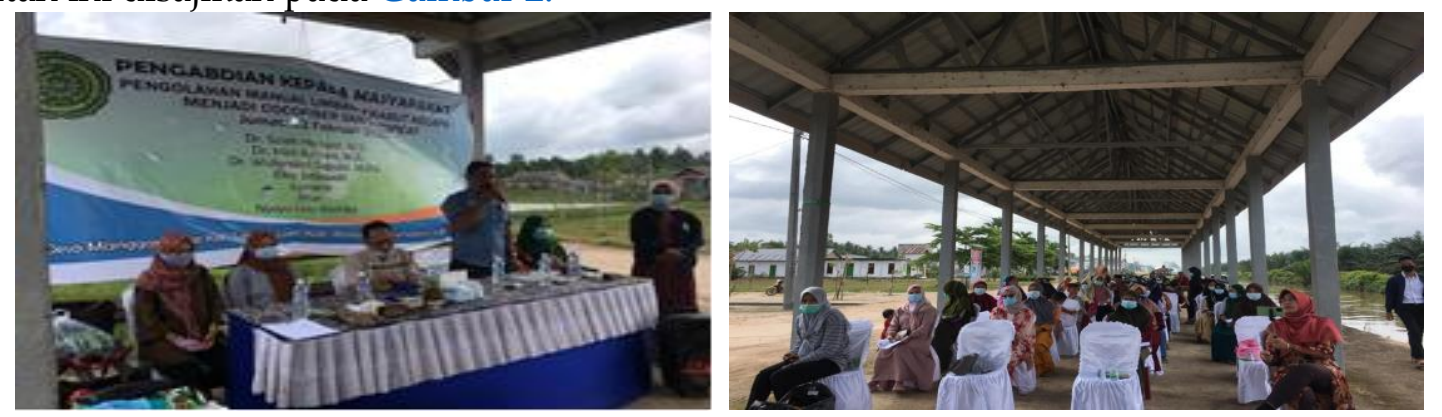

Gambar 2. Kegiatan Penyampaian Materi PKM

\section{Praktik Pembuatan Coco fiber dan Coco peat, serta Kokedama}

Proses pembuatan coco fiber dan coco peat sebenarnya sudah dimulai sejak satu minggu sebelum kegiatan PKM dilakukan. Hal ini karena proses pengolahannya membutuhkan waktu sekitar 5 hari perendaman dan dilanjutkan dengan kegiatan penjemuran. Setelah dijemur serabut kelapa dipukul-pukul agar coco fiber dan coco peat terpisah. Adapun kegiatan pengolahan serabut kelapa disajikan pada Gambar 3.
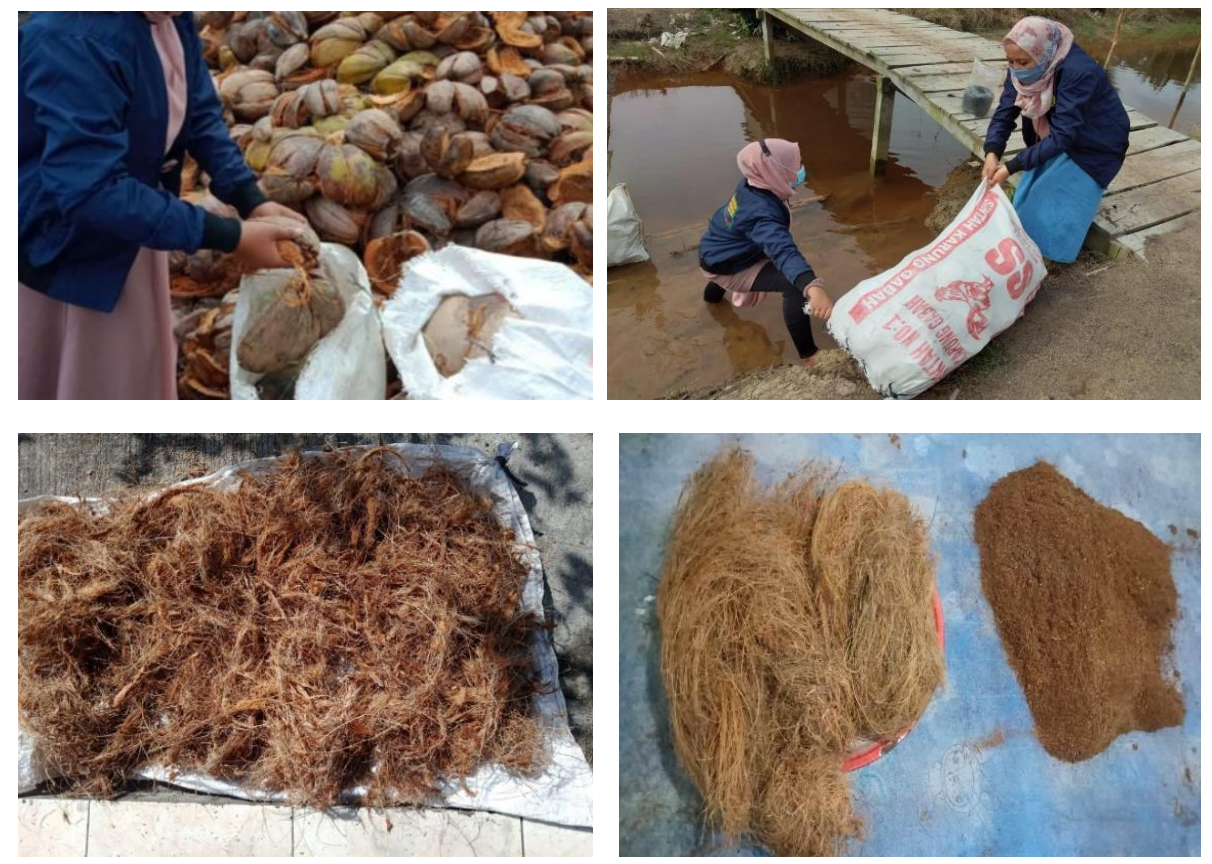

Gambar 3. Pengolahan Serabut Kelapa Menjadi Coco fiber dan Coco peat 
Setelah masyarakat paham tentang pengolahan pengolahan serabut kelapa dilanjutkan dengan kegiatan pembuatan kokedama. Sebagaimana telah disebutkan bahwa salah satu manfaat dari limbah serabut kelapa adalah untuk pembuatan media tanam. Oleh karena itu, keterampilan pembuatan kokedama dilatihkan agar limbah serabut kelapa yang melimpah di Desa Manggar Raya dapat berkurang serta menciptakan lapangan pekerjaan baru bagi masyarakat. Adapun fotofoto kegiatan pelatihan pembuatan kokedama disajikan pada Gambar 4.
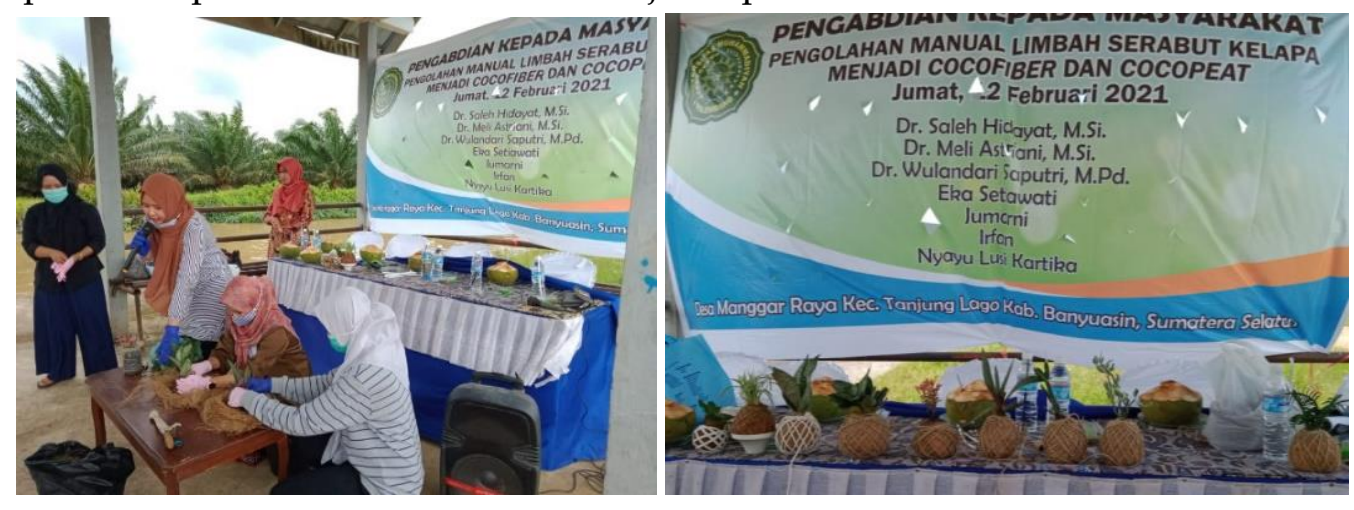

Gambar 4. Kegiatan Pelatihan Pembuatan Kokedama

\section{Evaluasi dan Pemberian Reward}

Kegiatan evaluasi dilakukan dengan pemberian angket respon kepada warga masyarakat yang berpartisipasi dalam kegiatan PKM ini. Demografi peserta kegiatan PKM ini disajikan pada Tabel 1 sebagai berikut.

Tabel 1. Demografi Peserta

\begin{tabular}{lcc}
\hline \multicolumn{2}{c}{ Demografi } & Jumlah $(\mathbf{n}=\mathbf{2 1})$ \\
\hline Usia & & \\
& 20-30 tahun & 7 orang \\
& 31-40 tahun & 8 orang \\
& $41-50$ tahun & 6 orang \\
\hline Pendidikan Terakhir & & \\
\hline & SD & 5 \\
& SMA & 4 \\
& D3 & 10 \\
S1 & 1 \\
\hline Pekerjaaan & & \\
& IRT dan Tani & 19 \\
& Guru & 1 \\
& Bidan & 1 \\
\hline
\end{tabular}

Berdasarkan Tabel 1, mayoritas peserta pelatihan adalah $71,4 \%$ peserta berada pada usia produktif (15 orang), 90,4\% peserta tidak mengenyam pendidikan tinggi, dan 90,4\% peserta berprofesi sebagai IRT dan tani. Dengan demikian, pelatihan ini diyakni dapat menambah keterampilan peserta untuk membantu kesejahteraan keluarga. Hasil pengisian angket dirangkum dan disajikan pada Tabel 2 berikut. 
Tabel 2. Rangkuman Hasil Pengisian Angket Respon Peserta

\begin{tabular}{|c|c|}
\hline Jawaban & Jumlah $(n=21)$ \\
\hline Materi pelatihan yang diberikan merupakan hal baru & 20 orang \\
\hline $\begin{array}{l}\text { Belum mengetahui pengolahan sabut kelapa menjadi coco } \\
\text { fiber dan coco peat }\end{array}$ & 18 orang \\
\hline $\begin{array}{l}\text { Setelah mendapat pelatihan peserta mengetahui definisi } \\
\text { dan manfaat coco fiber }\end{array}$ & 17 orang \\
\hline Peserta puas dengan pelatihan pembuatan kokedama & $\begin{array}{l}9 \text { orang sangat puas } \\
12 \text { orang puas }\end{array}$ \\
\hline $\begin{array}{l}\text { Peserta mendapat keterampilan baru pembuatan } \\
\text { kokedama }\end{array}$ & 21 orang \\
\hline Waktu pelatihan & $\begin{array}{c}6 \text { orang cukup } \\
15 \text { orang seimbang antara materi dan tugas }\end{array}$ \\
\hline
\end{tabular}

Berdasarkan Tabel 2 dapat disimpulkan bahwa peserta memberikan respon yang sangat baik terhadap kegiatan PKM yang telah dilakukan. Namun, peserta memberikan saran untuk menggunakan infoccus untuk kegiatan PKM ke depannya agar sehingga lebih menarik. Pada akhir kegiatan diadakan kegiatan pemberian doorprize kepada peserta kegiatan yang mampu membuat Kokedama paling baik dan yang mampu menjawab pertanyaan seputar coco fiber dan coco peat. Kegiatan juga ditutup dengan pemberian kenang-kenangan kepada Kepada Desa Manggar Raya dan foto bersama yang disajikan pada Gambar 5.

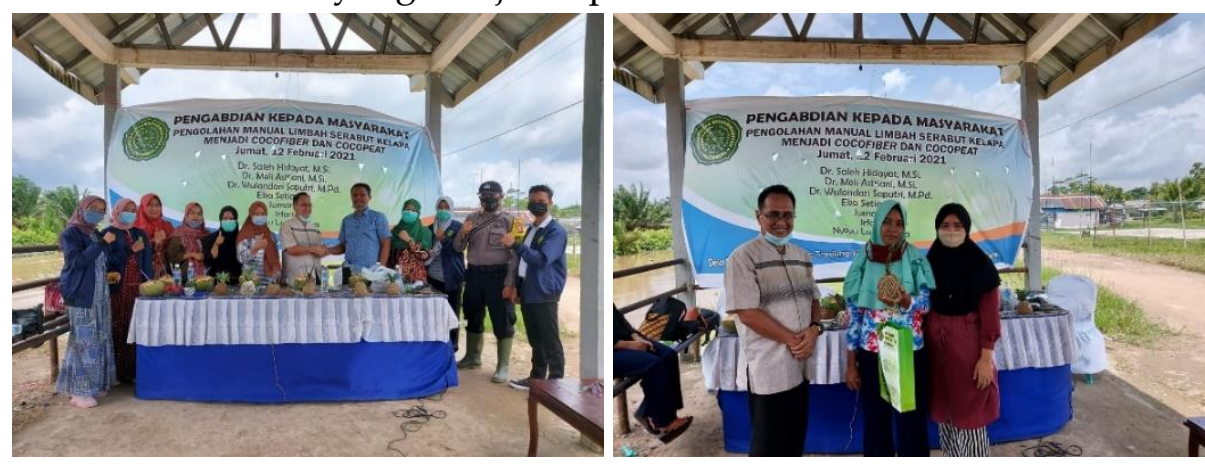

Gambar 5. Kegiatan Penutupan dan Pemberian Reward kepada Peserta Pelatihan

\section{KESIMPULAN}

Kegiatan pengolahan serabut kelapa mendapat respon positif dari para peserta kegiatan. Sebanyak $85 \%$ peserta yang awalnya belum mengetahui cara mengolah serabut kelapa menjadi tahu proses pengolahan serabut kelapa menjadi coco fiber dan coco peat, bahkan mereka diberi keterampilan membuat pot tanaman hias dari serabut kelapa. Prospek bisnis kedepannya agar Desa Manggar Raya kelak menjadi sentra industri pengolahan serabut kelapa di Sumatera Selatan. Produk yang dihasilkan berupa coco fiber dan coco peat pemasarannya melalui media sosial di daerah sekitar Kota Palembang. Hasil dari penjualan ini nantinya diharapkan dapat membeli alat pemisah serabut kelapa guna mempercepat proses produksi dibandingkan secara manual.

\section{UCAPAN TERIMA KASIH}

Terima kasih kepada Lembaga Penelitian dan Pengabdian Kepada Masyarakat (LPPM) Universitas Muhammadiyah Palembang yang telah memberikan dukungan pendanaan untuk pelaksanaan PKM Kolaboratif Dosen dengan Mahasiswa KKN ke-55. Terima kasih juga disampaikan kepada masyarakat di Desa Manggar raya, Kecamatan Tanjung Lago, Kabupaten Banyuasin, Sumatera Selatan sehingga terlaksana pengabdian ini dengan baik. 


\section{DAFTAR PUSTAKA}

Allwar, A., Prakoso, N. I., \& Laksono, S. (2018). KKN-PPM Pengolahan Limbah Kelapa di Watuduwur, Bruno, Kabupaten Purworejo. Asian Journal of Innovation and Entrepreneurship, 30(3), 217-222.

Astuti, E. (2019). Pelatihan Myob Accounting Version 19 Pada Himpunan Mahasiswa Pendidikan Akuntansi. Jurnal Pengabdian Kepada Masyarakat, 16(1), 10-16. https://doi.org/https://doi.org/10.21009/sarwahita.161.02

Dalimunthe, M. B., Dewi, R., Triono, M. A. ., Purnama, D., \& Hendri, Panggabean, F. Y. (2019). Penerapan Ipteks untuk Pengembangan Potensi Limbah Tempurung sebagai Upaya Peningkatan Pendapatan Masyarakat. Jurnal Pengabdian Pada Masyarakat, 4(2), 163-170.

Darmayanti, N. W. S., Sadia, W., Studi, P., Sains, P., Sarjana, P. P., \& Ganesha, U. P. (2013). Pengaruh Model Collaborative Teamwork Learning terhadap Keterampilan Proses Sains dan Pemahaman Konsep Ditinjau dari Gaya Kognitif. E-Journal Program Pascasarjana Universitas Pendidikan Ganesha, 3(2).

Efrita, E., Yawahar, J., \& Feriady, A. (2020). Pembuatan Coco peat Sebagai Upaya Peningkatan Nilai Tambah Sabut Kelapa. Jurnal Pengabdian Masyarakat Bumi Rafflesia, 3(3), 406-416.

Garneti, A. E. (2017). Analisis strategi pemasaran dalam upaya peningkatan volume penjualan tanaman hias boneka lumut dengan media tanam kokedama pada UMKM Planter Craft Bandung. Universitas Brawijaya.

Hamidah, S. (2015). Sayuran dan Buah Serta Manfaatnya Bagi Kesehatan Disampaikan dalam Pengajian Jamaah Langar Mafaza Kotagede Yogyakarta. Fakultas Teknik Universitas Negeri Yogyakarta, 1-10.

Hanum, M. S. (2015). Eksplorasi limbah sabut kelapa (Studi Kasus: Desa Handapherang Kecamatan Cijeunjing Kabupaten Ciamis). E-Proceeding of Art and Design, 2(2), 932.

Haryanto, D., \& Prasetyo, H. (2019). Penguatan Ekonomi Mikro Berbasis Variasi Produk Olahan Sabut Kelapa. Warta Pengabdian, 13(1), 13-21.

Indahyani, T. (2011). Pemanfaatan limbah sabut kelapa pada perencanaan interior dan furniture yang berdampak pada pemberdayaan masyarakat miskin. Humaniora, 2(1), 15-23.

Juariyah, B. (2010). (2010). pentingnya profesi wirausaha di Indonesia. Jurnal Ekonomi \& Pendidikan, $58-81$.

Novianti, D., \& Pertiwi, W. E. (2018). Implementasi Sanitasi Lingkungan di Sekolah Dasar: Laporan Inspeksi 2018 dari Kecamatan Kramatwatu, Kabupaten Serang, Provinsi Banten. Jurnal Kesehatan Lingkungan, 11(3), 175-188.

Persada, A. G., \& Anggita Ramadhani, C. (2015). Meningkatkan Kesadaran Dalam Berwirausaha Melalui Potensi Hasil Panen (Mie Tomat). Jurnal Inovasi Dan Kewirausahaan, 4(2), 2089-3086.

Saputra, N. E., Hernanda, H. B., Nurhuda, N., Ridwan, F. N., \& Ardhi, M. W. (2019). Pelatihan Bioentrepreneurship melalui Pembuatan Kokedama di Panti Asuhan Anak Luar Biasa Asih Madiun. CARADDE: Jurnal Pengabdian Kepada Masyarakat, 2(1), 101-104. https://doi.org/10.31960/caradde.v2i1.191.\%0A

Sepriyanto., \& Subama, E. (2018). Pengaruh Perlakuan Sabut Kelapa terhadap Hasil Coco fiber dan Coco Peat. Jurnal Inovator, 1(2), 22-25.

Sukarman, S., Kainde, R., Rombang, J., \& Thomas, A. (2012). Pertumbuhan bibit sengon 
(Paraserianthes falcataria) pada berbagai media tumbuh. Eugenia, 18(3).

Sulistyono, S. (2012). Pemanasan global (Global Warming) dan hubungannya dengan penggunaan bahan bakar fosil. Swara Patra, 2(2).

Supraptiningsih, L. K., Hattarina, S. (2018). PKM Kelompok Industri Pengolahan Limbah Sabut Kelapa (Coco peat) di Kabupaten dan Kota Probolinggo Provinsi Jawa Timur. Jurnal Ilmiah Pengabdian Pada Masyarakat, 2(2), 22-38.

Trahutami, S. ., \& Wiyatasari, R. (2019). Pengenalan dan Pelatihan Penanaman Dengan Teknik Kokedama Untuk Ibu-Ibu PKK. Harmoni, 3(2), 36-39.

Trianto, M., Marisa, F., \& S. (2020). Keanekaragaman jenis rayap pada perkebunan kelapa sawit dan perkebunan karet di Kabupaten Banjar, Kalimantan Selatan. Jurnal Biologi Makassar, 5(2), 199-209.

Widoyono. (2011). Penyakit Tropis Epidemologi, Penularan, Pencegahan \& Pemberantasannya. Erlangga. 